\title{
Modelos causais e a escrita da história*
}

\section{Causal models and the writing of history}

\author{
Moisés Antiqueira \\ mantiqpira@yahoo.com.br \\ Professor adjunto A \\ Universidade Estadual do Oeste do Paraná \\ Colegiado de História \\ Rua Pernambuco, 1777 - Jd. Universitário \\ Brasil
}

\section{Resumo}

Os historiadores estabelecem relações causais a fim de explicar a ocorrência de eventos e processos históricos. Diante disto, propomos, em primeiro lugar, definir em que consistiria a noção de causa no âmbito dos estudos históricos, bem como as possíveis maneiras a partir das quais os historiadores lidam com a multiplicidade causal. Nesses termos, o modelo de "frequência relativa" esboçado por Ernest Nagel oferece uma ferramenta que propicia uma reflexão acerca do grau de importância que os historiadores conferem às diferentes condicionantes por eles elencadas. Tendo em vista tais pressupostos, analisaremos, à guisa de ilustração, os esquemas explicativos que Perry Anderson e Moses Finley formularam em relação a uma problemática específica, qual seja, o "declínio" do escravismo antigo, assinalando as possibilidades de aplicação de referenciais comuns à filosofia da ciência que permitam uma maior compreensão a respeito da forma como se escreve a história.

\section{Palavras-chave}

Causalidade; Escrita da história; Explicação histórica.

\begin{abstract}
Historians have resorted to different forms of causal relations in order to explain historical events or processes. This article intends to discuss the issue of causality in history and to indicate possible ways some historians may handle the plurality of causes. In these terms, the "relative frequency" model outlined by Ernest Nagel provides a tool that enables a reflection on the level of importance ascribed by historians to the different causal conditions that they find. Bearing these assumptions in mind, I will analyze, by way of illustration, the explanatory models formulated by Perry Anderson and Moses Finley regarding a specific issue, namely the "decline" of the ancient slavery system, and I will point out to possibilities of applying common referentials to the philosophy of science, which may further our understanding of historical writing.
\end{abstract}

\section{Keywords}

Causality; History Writing; Historical explanation.

Recebido em: 12/4/2013

Aprovado em: 9/10/2013

\footnotetext{
Agradeço ao editor e aos pareceristas da $H H$ pelos comentários e sugestões, que permitiram que eliminássemos certas dificuldades que constavam no texto original.
} 


\section{O problema das causas na história}

"Por que 1789?" significa "Quais as causas de 1789?"; aparentemente, tais causas seriam uma cadeia infinita que se estende para trás e para o exterior e que você precisa penetrar, não obstante o fato de que nenhum método (e nenhuma vivência) conseguiria proporcionar-lhe pontos de apoio lógicos ou definidos para uma explicação suficiente e necessária (JENKINS 2011, p. 85).

Com tais palavras, Keith Jenkins alerta, tomando a Revolução Francesa como um exemplo dentre tantos outros, para a maneira não problemática e pouco rigorosa pela qual os historiadores abordam a questão da relação entre "causa" e "efeito" ao elaborarem suas narrativas. Na verdade, a argumentação desenvolvida por ele coloca em xeque algumas das bases epistemológicas sobre as quais se assenta o ofício do historiador: questiona a própria legitimidade e logicidade da utilização do conceito de causa no que se refere à escrita da história.

Contudo, a despeito da análise de Jenkins, partimos do princípio de que a análise causal mantém-se no horizonte teórico que norteia o trabalho dos historiadores (muito embora reconheçamos que não haja maior consenso acerca da associação entre explicação e causalidade no que diz respeito à produção do saber histórico). ${ }^{1}$ A fim de ilustrarmos essa afirmativa, tomemos um exemplo. No ano de 2002, foi publicada uma obra que despertou grande atenção em meio ao campo da historiografia brasileira. Tratava-se do livro Maldita guerra, de autoria de Francisco Doratioto, cujo enfoque recaía sobre a Guerra do Paraguai (1864-1870) (DORATIOTO 2002). O motivo que teria suscitado tamanho interesse pode ser verificado em uma resenha que José Murilo de Carvalho compôs acerca do referido estudo. Nela se salientava que "o ponto central que costura a narrativa de Doratioto é o das razões" que levaram ao conflito externo que marcou a história do Brasil durante o Segundo Reinado (CARVALHO 2003, p. 5). Mediante tal apontamento, Carvalho indiretamente sublinhava uma das dimensões cruciais que permitem definir o labor historiográfico, qual seja, o estabelecimento de um conjunto de relações causais que visam esclarecer a ocorrência de determinados eventos.

Faz-se oportuno, porém, nos interrogarmos a respeito da própria noção de causalidade. Em que consistiria a ideia de "causa"? A despeito das suspeitas que pairam sobre o conceito, desde as objeções levantadas por David Hume no Setecentos - de que os fenômenos se sucedem uns aos outros, sem que se possa observar uma conexão entre eles - é comum pensarmos que toda ciência não somente deva descrever, mas igualmente indicar porque as coisas ocorrem. $\mathrm{O}$ ato de explicar algo implicaria, assim, o apontamento de algumas informações

\footnotetext{
${ }^{1}$ No desenvolvimento da atividade de pesquisa, as explicações não se restringem à resposta de uma pergunta do tipo "Por quê", mas outras questões, como "O quê", também requerem uma explicação. William Dray destaca que o "explicar o que" pode envolver uma exposição minuciosa de um dado evento, no bojo da qual elementos já conhecidos poderiam ser reorganizados a ponto de serem oferecidas novas possibilidades de interpretação acerca do acontecimento em questão. Tal procedimento não carecia abranger, logo, uma resolução que explicitasse os motivos que levaram à ocorrência do mesmo (DRAY 1995, p. 495).
} 
a respeito do modo como determinada ação foi acarretada (GODFREY-SMITH 2003, p. 195). Todavia, vale sublinhar, como o faz Osvaldo Pessoa Júnior, que a indicação de uma eventual correlação entre dois eventos não preconiza a formação de uma relação causal (PESSOA JúNIOR 2006, p. 32). Ademais, é possível reconhecer a ocorrência de um fenômeno sem que se saiba o que haveria de tê-lo causado.

Diante do exposto, concluí-se que nem sempre resulta claro distinguir o que causou o quê. Ademais, uma explicação satisfatória não se assenta, pura e simplesmente, sobre um arrolamento de possíveis causas; antes, requer que sejam sinalizados um ou mais fatores que, no todo, sejam ajuizados como relevantes para a realização de um evento. Portanto, adentramos na seara dos efeitos. Em ciência, pode-se explicar um conjunto de fatos ao subordiná-lo a uma gama de princípios ou padrões gerais previamente estabelecidos ou ao se delimitar a trama causal que levou à sua concretização. Desta forma, Peter Godfrey-Smith assinala que a noção de explicação deve ser regida por uma perspectiva pluralista, uma vez que operaria conforme as peculiaridades dos diferentes campos científicos (GODFREY-SMITH 2003, p. 196-197). Neste sentido, a ideia de explicação envolve uma espécie de contextualismo, de modo que diferentes ramos do conhecimento postulam critérios próprios para que se aceitar aquilo que configuraria uma explicação adequada. Por isso mesmo, autores como Marc Bloch não se furtaram em destacar que as relações de causa e efeito se situariam como "ferramenta do conhecimento histórico", as quais, todavia, exigiriam "uma tomada de consciência crítica" por parte dos historiadores (BLOCH 2001, p. 155).

Por conseguinte, não podemos deixar de nos remeter aos pontos de vista advogados por John Lewis Gaddis. Este reitera a ótica de que não há regra alguma que normatize a qual ponto os historiadores deveriam se atentar quando traçam as causas de qualquer evento ou processo histórico. Todavia, continua Gaddis, os historiadores usualmente operam por meio do "princípio de diminuição da relevância". Significa dizer que, quanto maior o intervalo temporal a separar uma causa de sua consequência, presume-se que tal causa se afigure menos importante. No entanto, é preciso assinalar que todo evento se circunscreve a um dado contexto, do que resulta que uma causa "próxima", "excepcional", se insere em uma trama dependente de causas "remotas", "gerais", mais recuadas no tempo. A causa que os historiadores identificam como "excepcional" equivaleria, observados os processos que conduzem a estruturas particulares, àquele ponto em que esses mesmos processos tomam um curso distinto e imprevisto (GADDIS 2002, p. 96-97). Nestes termos, a causa em história pode ser pensada como o antecedente que, em meio a uma gama de condições gerais, é ressaltado enquanto elemento diferencial (BLOCH 2001, p. 156).

Deste modo, faz-se escusado salientar que não concebemos a plausibilidade de uma plena cisão entre a narrativa do historiador e a realidade que ele se dispõe a investigar, por mais complexo que o seu objeto se revele. A estrutura da ação - ou seja, a existência de uma sequência que contemple início, meio e fim - corresponde a algo compartilhado tanto por indivíduos e grupos sociais 
quanto pelos textos que deles se ocupem. "Quem propõe a descontinuidade", escreve Ciro Flamarion Cardoso, "afirmando que na vida real não há começo, meio e fim, esquece não só o nascimento e a morte como [...] inúmeras formas menos definitivas de estruturações dotadas de inícios e conclusões" (CARDOSO 1998, p. 56).

Neste sentido, embora não se possa ignorar o fato de que os historiadores elaboram narrativas que não se encontram diretamente observáveis no próprio passado, a história não deve ser tomada enquanto relato ficcional, como outro qualquer: as narrativas históricas apresentam relações causais que não equivalem a construções livremente formuladas, mas antes são edificadas a partir de provas, controles e operações cognitivas sobre as quais se alicerça a sua condição de conhecimento verdadeiro (CHARTIER 2010, p. 13). Logo, reputamos ser lícito que os historiadores, na consecução de seu ofício, exponham quais seriam os possíveis fatores, ou antecedentes, relativos ao desenrolar de certos acontecimentos ou processos históricos. Ao fazê-lo, os historiadores promovem uma "hierarquia de causas que fixaria suas relações recíprocas e talvez decid[am] que causa, ou categoria de causas, deveria ser vista como [...] a causa fundamental" (CARR 1982, p. 77).

Não obstante, cabe retomarmos as afirmações de Jenkins, com as quais abrimos nosso texto. Embora Jenkins não estipule modelo argumentativo algum que pudesse substituir ou suplantar o estabelecimento de redes causais na escrita da história, as palavras dele nos conduzem a considerar a ausência 14 de reflexões mais aprofundadas, por parte dos historiadores, a respeito dos preceitos que adotam - consciente ou inconscientemente - ao atribuir maior ou menor significado às causas que articulam à ocorrência de um evento. Almejamos, assim, propor uma análise que nos possibilite compreender de que modo os historiadores procuram articular e sustentar as explicações causais apresentadas nos meandros dos textos que compõem.

Para tanto, nos serviremos de referenciais comumente empregados no âmbito da filosofia da ciência. Resgataremos um dos modelos causais tipificados por Ernest Nagel em seu clássico artigo sobre a "lógica da análise histórica" (NAGEL 1995b). Tal modelo se volta para a averiguação da "frequência relativa" com a qual um fenômeno ocorreria, levando-se em conta a realização dos fatores que the dariam origem. Somado a isto, veremos em que medida o recurso a generalizações e condicionais contrafatuais tornaria possível avaliar a maneira pela qual os historiadores conferem diferentes graus de importância às explicações fornecidas a respeito da ocorrência de um dado acontecimento.

\section{O modelo de "frequência relativa" de Ernest Nagel}

Os estudos desenvolvidos por Nagel centram-se na área da epistemologia da ciência. Ao abordar a problemática geral da explicação científica, Nagel se voltou ocasionalmente para a questão da causalidade e da formulação de explicações em história. As contribuições de pensadores como Nagel se articulavam à denominada "filosofia analítica da história", corrente que havia ganhado força no universo acadêmico europeu (em especial o britânico) e estadunidense na 
primeira metade do século $X X$, em oposição às filosofias da história que, até aquele momento, se caracterizavam por um nítido viés especulativo. A "filosofia analítica da história" compreenderia reflexões orientadas para a fundamentação de um estatuto científico para a história, ocupando-se de questões tangentes à prática do historiador e a relação deste com o seu objeto.

Entretanto, de acordo com Cristiano Alencar Arrais, não existe consenso quanto aos elementos que definiriam as bases dessa tendência analítica. A despeito disso, tal corrente é frequentemente associada ao modelo nomológico-dedutivo que o filósofo da ciência Carl Gustav Hempel havia proposto no que se referia à construção de esquemas explicativos no caso específico da história (ARRAIS 2010). Em "The function of general laws in history", breve artigo escrito no ano de 1942 e que passaria a gozar de grande influência, Hempel almejava conferir à pesquisa histórica o teor de objetividade comum às ciências ditas naturais (HEMPEL 1995).

Do ponto de vista lógico, Hempel defendia a unidade entre as ciências da natureza e do homem. Afirma ele que a história, tanto quanto a física ou a química, operava a partir de generalizações, as quais corresponderiam a "hipóteses universais" tacitamente aceitas e que permitiriam relacionar dadas características da vida individual e/ou coletiva com certos elementos que igualmente faziam parte da experiência humana. Daí que sustentasse o uso do "modelo da cobertura por leis" (covering law model) para o fornecimento de explicações em história: a ocorrência de um evento histórico poderia ser deduzida uma vez especificadas as condições iniciais (quer dizer, se se apontassem os fatos particulares ao acontecimento) e uma ou mais leis universais, empiricamente comprovadas, que "cobrissem" o evento em questão (HEMPEL 1995, p. 423).

Todavia, Hempel postula que as análises explanatórias em história não cumpririam de modo perfeito os preceitos inerentes a esse saber nomológico, em especial no que respeita aos padrões de previsibilidade que o emprego de regularidades gerais haveria de pressupor. Isto o conduz ao argumento de que os historiadores ofereceriam, quanto muito, um "esboço de explicação causal" e, neste sentido, não conseguiriam indicar senão de maneira imprecisa quais seriam as leis e as condições iniciais julgadas importantes para a realização de um evento (HEMPEL 1995, p. 429).

Portanto, no entender de Hempel, a construção do conhecimento histórico não poderia se efetuar por intermédio de um esquema estritamente dedutivo. Contudo, Alun Munslow afirma que, para Hempel, o "esboço de explicação causal" delineado pelos historiadores haveria de se escorar sobre as prováveis leis que governariam o comportamento humano, a partir das quais seriam inferidos o significado e as possíveis causas dos eventos (MUNSLOW 2006, p. 70). Aviezer Tucker, porém, sublinha a ótica de que o exame empírico das explicações oferecidas pelos historiadores não propiciaria a descoberta de quaisquer "leis de cobertura" que sejam e, ainda que pudessem ser assinaladas tais leis, estas figurariam apenas como substitutivos abstratos empregados no lugar de termos concretos, os quais de modo algum esclareceriam porque os historiadores consideram algumas explicações mais adequadas do que outras. 
Logo, conclui Tucker, "se os historiadores escrevem que Augusto queria se tornar imperador porque ele era ambicioso, nós não estaríamos mais bem informados se disséssemos que existe uma vaga lei geral que determina que pessoas ambiciosas buscam o poder" (TUCKER 2004, p. 189).

No entanto, estudiosos como Clayton Roberts argumentam que o fato de as narrativas historiográficas não se pautarem explicitamente em leis gerais não invalidaria o "modelo de cobertura por leis". A presença de regularidades se daria de modo elíptico no interior dos textos elaborados pelos historiadores e, ainda que as explicações históricas somente possam ser consideradas parciais e prováveis, não deixariam de se configurar enquanto explicações (ROBERTS 1996, p. 9). Porém, continua Roberts, a complexidade dos eventos e dos processos históricos - dotados de aspectos extremamente variados e que abrangem diferentes atores sociais - faz com que os historiadores se afastem da busca por explicá-los mediante a recorrência a certas condições iniciais universalizáveis (ROBERTS 1996, p. 10).

Mas e quanto a Nagel? A princípio, faz-se preciso reconhecer que, de fato, Nagel parte de uma perspectiva similar àquela advogada por Hempel em favor do unitarismo epistemológico das ciências. Desta forma, Nagel declara que os historiadores também exerceriam o seu ofício "mediante a aceitação e utilização de leis gerais". Tal se notaria, de acordo com ele, no tocante à utilização de conceitos em meio aos estudos históricos: poder-se-ia falar em "Revolução Francesa" ou "Revolução Russa" somente se reconhecida a dimensão nomológica articulada ao emprego do conceito de "revolução". Em outras palavras, o uso de um arcabouço conceitual sublinharia o aspecto geral e a similaridade existente entre lugares e épocas históricas variadas (NAGEL 1995b, p. 458-459).

Por seu turno, o próprio Nagel enfatiza a noção de que os historiadores não aceitam a ótica de que sua tarefa residisse no estabelecimento de leis gerais. Assim, pode-se notar uma tentativa de adequação que, em certo sentido, o distanciava de Hempel. Nagel inclusive afirmaria que o "modelo de cobertura por leis" não era capaz de explicar eventos coletivos e significativamente complexos (NAGEL 1979, p. 574), como o são aqueles com os quais, destaquemos, os historiadores haveriam de lidar. Em suma, ainda que os historiadores trabalhassem a partir de generalizações, quando da busca por formular causas singulares que esclarecessem as inter-relações entre ações específicas, não teriam por foco a procura por tais leis, mas antes se ocupariam da descrição de eventos particulares (NAGEL 1995b, p. 459). É por isso que Arrais garante que epistemólogos como Nagel e Morton White assinalam a ideia de que algumas explicações em história poderiam ser consideradas adequadas mesmo que não remetessem a um corpo de leis gerais, abrindo a possibilidade para o apontamento de condicionantes causais singulares (ARRAIS 2010).

Diante do exposto, faz-se oportuno nos remetermos às ideias de Max Weber. Ao refletir acerca da metodologia no campo das "ciências da cultura", dentre as quais enumerava a história, Weber declara que o problema da causalidade de um fenômeno histórico individual não incidiria sobre leis, mas antes sobre "conexões causais concretas". Dito de outra maneira, Weber esclarece que nos 
meandros das "ciências da cultura", o estudioso não se volta a uma fórmula para a qual subordinaria um fenômeno em específico e sim procura determinar "a que constelação particular [tal fenômeno] deve ser imputado como resultado". Trata-se do problema da imputação, isto é, da atribuição das causas dos fenômenos, que adquirem significância justamente em virtude de sua individualidade, das condições concretas que levaram à sua emergência (WEBER 2006, p. 54-55).

Portanto, conhecer eventuais leis da causalidade não poderia constituir o fim, mas, pelo contrário, o meio de estudo no que tange a áreas como a história. Salientar-se-ia a perspectiva de que o historiador também lidaria com conceitos genéricos abstratos ou estaria ciente da existência de regularidades. Por isso, Weber observa que

Se o conhecimento causal do historiador consiste numa imputação de certos resultados concretos a determinadas causas concretas, então é impossível uma imputação válida de qualquer resultado individual sem a utilização de um conhecimento "nomológico" - isto é, do conhecimento das regularidades das conexões causais (WEBER 2006, p. 55, grifos nossos).

Sendo assim, Weber postula que os historiadores operam a partir da hipótese de que um ou mais elementos individuais e singulares comportariam alguma importância para o resultado, quer dizer, para um fenômeno que se almejasse explicitar. Para cumprir com a tarefa de se avaliar a influência dos elementos que integram uma conexão causal, os historiadores procedem mediante um conhecimento do geral, daquilo que se pode geralmente esperar de um dos elementos que integram um conjunto causal. A natureza generalizante de uma explicação histórica se conecta, logo, aos efeitos dos elementos causais formulados pelos historiadores em seu trabalho de imputação.

Como recorda Fritz Ringer, a proposta weberiana de análise causal, no relativo às ciências que se ocupam da sociedade e do homem, situa a singularidade naquilo que é explicado, no sentido lógico de que o resultado de uma conexão causal não é geral (à maneira de uma lei da física, por exemplo) e pode ser razoavelmente localizado no tempo e no espaço. Nestes termos, a singularidade reside nos efeitos, e não nos antecedentes causais; a avaliação da relevância destes não excluiria uma dimensão probabilística e também contrafatual, procedimento que não se confunde, pois, com uma dedução efetuada a partir de leis invariáveis (RINGER 1997, p. 3).

Feito isto, tratemos de esmiuçar quais seriam os fundamentos pertinentes ao modelo causal de "frequência relativa", como definido por Nagel. Proclamando a possibilidade de se estabelecer uma ordem de importância relativa às condicionantes dos fenômenos sociais, Nagel apresenta os seguintes passos: primeiramente, parte-se da suposição de que os fatores causais, que rotularemos aqui como $\langle\mathrm{C} 1\rangle,\langle\mathrm{C} 2\rangle,\langle\mathrm{Cn}\rangle$, estão devidamente identificados por parte do historiador. Todos os condicionantes elencados devem acarretar, de uma forma ou de outra, a ocorrência de um fenômeno <E>. Neste caso, procede-se à construção de um esquema lógico, por intermédio do qual se ponderaria qual haveria de ser, dentre as hipóteses causais listadas, aquela tida 
como a mais relevante (ou fundamental) para que o fenômeno <E> aflorasse (NAGEL 1995b, p. 469).

O modelo de "frequência relativa" apregoa que não é necessária a presença conjunta e simultânea de todas as hipóteses causais para que <E> viesse a se concretizar. Neste caso, poder-se-ia preconizar, à guisa de argumentação, que a frequência relativa com que um fenômeno $<E>$ ocorre seria maior na presença de apenas uma das condições - a condição $\langle\mathrm{C} 1\rangle$, por exemplo - do que quando a condição <C2> ou outras fossem efetivadas. "Este é", sentencia Nagel, "o estado de coisas que muitas vezes se tem em mente quando se afirma que $[\langle\mathrm{C} 1\rangle]$ é uma determinante mais importante de $[\langle\mathrm{E}\rangle]$ do que $[<\mathrm{C} 2\rangle]$ " (NAGEL 1995b, p. 470). Em resumo, conforme esta proposta, a mensuração da importância dos fatores causais residiria na maior frequência com a qual uma relação de causa e efeito seria identificada pelo historiador, em face dos diferentes fenômenos com os quais ele se ocupa.

Em vista disto, apresentaremos uma possibilidade de reflexão, pautada no supramencionado modelo de Nagel, levando-se em conta a prática concreta dos historiadores, a qual ganha corpo sob a forma de uma narrativa. Selecionamos, para tanto, uma problemática comum aos estudos dedicados ao período hodiernamente qualificado como "Antiguidade Tardia". Trata-se da questão do "declínio"2 ou do enfraquecimento do emprego de mão de obra escrava na sociedade romana imperial. Desta maneira, trabalharemos com as obras de dois estudiosos distintos, a saber: Passagens da antiguidade ao feudalismo, originalmente lançada por Perry Anderson em 1974, ao lado de A economia antiga e Escravidão antiga e ideologia moderna, livros de Moses Finley que surgiram, respectivamente, nos anos de 1973 e 1980. Dito isto, cabe ressaltar que tamanha escolha se pautou, em especial, no fato de que as referidas obras se revelam amplamente acessíveis aos acadêmicos brasileiros, algo que permite que os referenciais causais que exporemos sejam confrontados com textos que dispõem de boa disponibilidade e fácil acesso em nosso país, dadas as versões em vernáculo existentes.

Faz-se preciso recordar, finalmente, que as conexões estabelecidas pelo historiador, no que tange à tarefa de se explicar um fenômeno dado, constituem inferências causais formuladas a partir dos efeitos constatados (COPI 1978, p. 412). Ou seja, os historiadores partem dos efeitos a fim de estipular quais seriam as possíveis causas que os teriam engendrado. No entanto, destaquemos, seguindo os passos de Adam Schaff, a advertência de que os historiadores não elaboram suas interpretações a partir dos fatos, mas antes das evidências às quais têm acesso. O ato de selecionar e organizar as mais variadas fontes constitui uma operação mediante a qual os historiadores conferem a certos eventos do passado a dimensão de acontecimentos históricos (SCHAFF 1995, p. 307). Portanto, tal empresa não se dissocia do próprio ato de se apontar

\footnotetext{
2Embora a palavra "declínio", como alerta Finley, careça de precisão metodológica para definir a redução na quantidade de escravos. Por não se tratar de uma categoria moral, mas antes corresponder a uma instituição social, não poderia haver um declínio da escravidão em si, e sim uma queda no número de indivíduos que se enquadrassem no estatuto jurídico de escravo (FINLEY 1991, p. 133).
} 
as "causas" e os "efeitos", no que se refere à tarefa de investigação efetuada pelos historiadores.

\section{Possibilidades de aplicação: o "declínio" do escravismo antigo segundo Perry Anderson e Moses Finley}

Tanto Anderson quanto Finley dão suporte à argumentação de que o início da crise do escravismo no Império romano poderia ser datado entre os séculos II-III d.C. (ANDERSON 1989, p. 79; FINLEY 1991, p. 137) - em que pese a abundante e crível evidência a nos alertar para o fato de que, mesmo no século IV d.C., a mão de obra escrava continuou a ser empregada em larga escala e sem que conhecesse significativo recuo (HARPER 2011, p. 4). ${ }^{3}$ Seja como for, uma vez delimitado o problema, Anderson e Finley procuram explicá-lo, de modo que ambos estabelecem, cada qual à sua maneira, quais seriam as causas que teriam condicionado à emergência do fenômeno assinalado.

\section{a) Perry Anderson}

Voltemo-nos, assim, para a análise proposta por Anderson. Alicerçado nos ditames do materialismo histórico, afirma ele que a desagregação do "modo de produção escravista" na Antiguidade correspondeu a um momento em que as contradições inerentes ao sistema se acirraram, ocasionando uma alteração profunda na infraestrutura econômica (e, pois, na superestrutura política, com a posterior dissolução do poder institucionalizado romano no Ocidente, a partir de meados do século $V$ d.C.).

Neste caso, a diminuição numérica da mão de obra escrava inviabilizou a manutenção do sistema produtivo tradicional. Ainda segundo Anderson, ao contrário do escravismo moderno, inserido na dinâmica do capitalismo ocidental, no mundo antigo não existiriam mecanismos internos responsáveis por assegurar a autorreprodução do sistema, pois que a estabilização uniforme da força de trabalho escrava revelar-se-ia inatingível. O labor escravo em si constituía obstáculo ao progresso técnico, tornando inócua a possibilidade de se alcançar um aumento de produtividade inversamente proporcional ao volume decrescente de escravos (ANDERSON 1989, p. 76).

Partindo desses pressupostos, Anderson aponta uma série de fatores cujo somatório será aqui denominado por "conjunto a" - para explicar o efeito, qual seja, o "declínio" da quantidade de escravos a partir do alvorecer da Antiguidade Tardia (ANDERSON 1989, p. 73-75). Podemos elencá-la do seguinte modo, indicando por $<\mathrm{C}>$ as condições que teriam ocasionado o efeito $<\mathrm{E}>$ ora escrutinado:

Condição <C1>: Nos dois últimos séculos da época republicana, Roma alicerçou a instalação de seu sistema imperial ao longo da orla mediterrânica.

\footnotetext{
3 Muito embora o próprio Finley (1991, p. 137-138) enfatizasse a permanência do sistema escravista até a época carolíngia, reconhecendo que a questão do "declínio" da utilização de braços escravos deve ser concebida como um processo gradual e difuso de transformação social. Por sua vez, Anderson salienta a ideia de que a escravidão-mercadoria constituiu a força de trabalho predominante, sobremaneira, nas províncias ocidentais do Império (ANDERSON 1989, p. 266). Deste modo, o "declínio" da escravidão não afetaria, de maneira uniforme, a totalidade do território imperial.
} 
Nos séculos I e II d.C., assistiu-se, por sua vez, à estabilização das fronteiras imperiais. Neste período, a expansão territorial romana efetivou-se somente em áreas periféricas, tais como a Germânia, a Dácia e a Mesopotâmia. Assim, a integração e consolidação de diversas áreas ao território do Império, paralela ao arrefecimento das guerras de conquista (que cessaram, basicamente, com as campanhas levadas a cabo pelo imperador Trajano Trajano [98-117 d.C.]), implicou a redução do volume de estrangeiros a escravizar, enquanto presas de guerra;

Condição <C2>: Incapacidade do comércio intraimperial no sentido de suprir as deficiências provocadas pela diminuição na quantidade de cativos, na medida em que os próprios negociantes de escravos se vinculariam às operações militares, com vistas ao abastecimento de seus estoques;

Condição <C3>: A aquisição de escravos a partir do comércio com a periferia bárbara mostrar-se-ia insuficiente para atender a demanda interna por mão de obra;

Condição <C4>: E, finalmente, a impossibilidade do estabelecimento de um regime de "procriação sistemática". Por um lado, a manutenção da prole escrava resultava em uma carga financeira improdutiva para o proprietário e, por outro, havia uma assimetria na composição dos escravos, redundando em baixo índice de reprodução. As mulheres eram consideradas inaptas para a maioria dos afazeres que demandavam maior esforço físico, de modo que as escravas seriam empregadas majoritariamente em tarefas domésticas. Além disso, os índices de crescimento vegetativo referente à população rural livre 20 eram baixíssimos e, logo, não poderiam compensar os pequenos percentuais de reprodução natural entre os escravos.

De imediato, pode-se constatar que Anderson imputou ao fenômeno analisado diversas causas, cujas raízes seriam, igualmente, variadas. No entanto, a condição $<\mathrm{C} 1>$ se escora em uma apreciação generalizante, tal como aclara Anderson: "[...] o suprimento de escravos dependia muito das conquistas estrangeiras, já que os prisioneiros de guerra provavelmente sempre haviam proporcionado a principal fonte de trabalho servil na Antiguidade" (ANDERSON 1989, p. 73). Tamanha generalização sustenta, logo, uma hipotética relação de causa e efeito. Conforme Edward Hallet Carr, uma explicação racional e válida para o labor historiográfico poderia estar atrelada a uma generalização, isto é, à possibilidade de sua aplicação para o esclarecimento de diversas situações históricas (CARR 1982, p. 89).

Ora, no campo das humanidades, o emprego de proposições gerais se assenta em bases mais vagas, se cotejadas com os preceitos inerentes aos modelos nomológicos-dedutivos de explicação científica. Todavia, como escreve Isaiah Berlin, as generalizações são aceitas em história na medida em que se mostrarem racionalizáveis, quer dizer, se coadunando à capacidade do ser humano de compreender os hábitos de pensamento e de ação que adquirem materialidade por intermédio das atitudes e das formas de conduta de homens e mulheres (BERLIN 2002, p. 83). Compete sublinhar que o recurso à generalização faz com que percamos de vista a diversidade, a riqueza e a profundidade que caracterizam as relações humanas - vide a assertiva de Anderson, que 
desconsidera as diferentes modalidades de trabalho dependente que podem ser verificadas no mundo antigo, como a escravidão por dívidas. No entanto, configura um mecanismo a partir do qual se fundamentam ajuizamentos mais precisos a respeito de uma dada situação que se observa na realidade pretérita.

Em suma, as generalizações derivam de abstrações que levam em conta elementos específicos, comumente observáveis em diferentes momentos e lugares, ainda que se deixe de lado um leque de características que possam despertar um interesse geral (BERLIN 2002, p. 77). Nestes termos, Anderson conferiu um ordenamento à multiplicidade causal por ele próprio esboçada. Seria, logo, a causa <C1> uma determinante dotada de maior peso para o aparecimento de $<\mathrm{E}>$ ?

Vejamos toda a questão sob outro prisma. Considerado o esquema explanatório formulado por Anderson, a condição $<\mathrm{C} 1>$ poderia ser julgada como a única causa suficiente para a realização de $<E>$ ? $^{4}$ Não exatamente, pois o decréscimo na quantidade de escravos poderia ser explicado pelos demais condicionantes $-<\mathrm{C} 2\rangle$ e, em especial, $<\mathrm{C} 3\rangle$ e $<\mathrm{C} 4\rangle-$ que integram o conjunto a, o qual, por sua vez, implicou a ocorrência de $<E>$. Ou seja, $<$ C1 $>$ não configuraria a única causa suficiente dentro do esquema postulado por Anderson. Entretanto, a mesma se revela necessária para a existência do conjunto a em sua totalidade, no sentido de que as demais condicionantes que o compõem se encontrariam, de algum modo, vinculadas ao fator $\langle\mathrm{C} 1\rangle$. A condição $<$ C2 $>$ se relaciona diretamente à perspectiva do término das guerras de conquista romanas. Por sua vez, a condição $<\mathrm{C} 3>$ também se relaciona com $\langle\mathrm{C} 1\rangle$, visto que a consolidação do limes imperial, a separar cidadãos romanos, de um lado, e "bárbaros", de outro, (embora, ressalvemos, não se tratasse de uma fronteira fixa e, menos ainda, intransponível) transformava os indivíduos que se situassem para além dos limites no objeto primordial de uma eventual obtenção de novos braços escravos.

Por fim, é possível notar que, dentro da argumentação proposta por Anderson, a condição <C4> igualmente se subordinaria à proposta contida em $<$ C1 $>$. Os métodos de "procriação sistemática" seriam desconsiderados quando confrontados com a grande quantidade de cativos que haviam afluído para o Império à época da transição da República para o Principado (séculos I a.C.-I d.C.). Neste caso, as conquistas romanas supriram a demanda por mão de obra, desestimulando a aplicação de meios internos para a reprodução física dos escravos. Sendo assim, diante do exposto, podemos afirmar que a condição <C1 $>$ emerge enquanto antecedente diferencial para a realização de <E $>$ na medida em que se afigura como o "elemento necessário de um conjunto suficiente", tomando de empréstimo a definição postulada por Pessoa Júnior no que tange ao estabelecimento de relações causais (PESSOA JúNIOR 2006, p. 31).

\footnotetext{
${ }^{4}$ De acordo com Irving Copi, as conexões causais podem ser apontadas tendo em mente a existência de certas condições, que podem ser definidas da seguinte maneira: uma condição necessária para a efetivação de um acontecimento corresponde a "uma circunstância em cuja ausência o evento não possa ocorrer". Por seu turno, "uma condição suficiente para a ocorrência de um evento é uma circunstância em cuja presença o evento deve ocorrer" (COPI 1978, p. 329).
} 
Desta maneira, analisemos por ora o conjunto a, agrupado em conformidade com os argumentos oferecidos por Anderson, servindo-se do modelo de "frequência relativa" advogado por Nagel. Vale recordar que a presença simultânea de todos os condicionantes apontados por Anderson não será tomada por necessária para a ocorrência de $\langle E\rangle$ - isto é, para que se concretizasse o decréscimo no universo de escravos no interior do Império romano. Poder-se-ia concluir que eventuais variações no fator causal <C1> acarretariam flutuações consequentes em <E> com uma frequência maior do que aquela que poderia ser observada na presença dos fatores $\langle\mathrm{C} 2\rangle,\langle\mathrm{C} 3\rangle$ e $<$ C4 $>$. Em outras palavras, à medida que as guerras de conquista propiciassem um notável contingente de cativos para os campos de cultivo e para as cidades romanas, não se constataria a queda no número de escravos. Isto significa que, se aplicássemos as condições $\langle\mathrm{C} 2\rangle,\langle\mathrm{C} 3\rangle$ e $\langle\mathrm{C} 4\rangle$ ao contexto da expansão de Roma na bacia do Mediterrâneo, a incidência de $<E>$ seria diminuta.

Ou seja, variações consideráveis em $\langle\mathrm{C} 2\rangle$, $<\mathrm{C} 3\rangle$ e $<\mathrm{C} 4>$ não produziriam alterações substanciais em $<E>$. Isto nos ajuda a compreender em que sentido a cessação das incursões militares ofensivas, por parte das forças romanas (condição <C1>), teria ocasionado, fundamentalmente, o "declínio" do escravismo (fenômeno <E>), dentro dos parâmetros estabelecidos por Anderson. Em meio à conjunção de causas, $\langle\mathrm{C} 2\rangle$, $\langle\mathrm{C} 3\rangle$ e $\langle\mathrm{C} 4\rangle$ poderiam, assim, ser entendidas enquanto condicionantes "de fundo".

\section{b) Moses Finley}

Mas e quanto à abordagem defendida por Finley diante da mesma problemática? Finley reduz o universo de causas possíveis a duas (que designaremos como "conjunto $\beta$ "), já que, conforme ele próprio aduz, ambas conteriam "um elemento de verdade" (FINLEY 1986, p. 119). Assim, temos:

Condição <C1> : A estabilização das fronteiras imperiais durante a época do Principado e a finalização das guerras de conquista romanas, comprometendo o abastecimento do mercado de mão de obra escrava.

Condição <C2>: O aumento da disponibilidade de mão de obra interna, vinculada a uma transformação estrutural da sociedade como um todo, em que a situação das camadas inferiores sofreria cumulativa depressão. A cidadania no mundo romano, após a ascensão de Augusto (27 a.C-14 d.C.), perderia gradativamente a sua importância e, por cerca de três séculos (I-III d.C.), os direitos políticos intrínsecos à cidadania desapareceriam. O exército, constituído por profissionais, aliviava os homens livres dos encargos referentes ao recrutamento militar; ao mesmo tempo, porém, extraía-se dos homens livres a possibilidade de fazer frente às pressões do Estado. Os encargos estatais, traduzidos em taxações crescentes, recaíam especialmente sobre os mais depauperados desses indivíduos. Neste ensejo, se gestou a figura do colono, cidadão pobre que, para cumprir com as obrigações fiscais, acabou por permanecer atrelado à terra que por ele era cultivada, independente do estatuto de homem livre que usufruísse. Na prática, o colono se situaria no mesmo plano que o escravo, uma vez que se encontrava privado de sua liberdade, dada à 
vinculação à terra, e submetido às mesmas penalidades que incidiam sobre os indivíduos em condição servil.

Diante do exposto, nota-se que Finley e Anderson compartilham a perspectiva de que o fim da expansão territorial romana resultou no "declínio" do escravismo em Roma (o efeito <E>). Significa dizer que tal condicionante assumiria, dentro do esquema explanatório de Finley, dimensão semelhante àquela que pode ser destacada na obra de Anderson? A resposta a essa questão é negativa e, assim sendo, demonstraremos de que maneira Finley recorre a um pressuposto contrafatual a fim de minimizar a relevância do mencionado fator causal.

Ao contrário de Anderson, Finley não reputa impossível a sistematização, no que concernia à Antiguidade greco-romana, de um programa de reprodução natural dos escravos que pudesse compensar a redução no número de cativos de guerra ou de escravos importados - preposição contrafatual que rotularemos como condição <F>. Para tanto, Finley se escora sobre o exemplo fornecido pelos estados escravocratas do Sul dos Estados Unidos nos princípios do século XIX, que haviam adotado políticas de reprodução sistemática em resposta ao virtual impedimento do tráfico negreiro (FINLEY 1986, p. 119-120).

Sendo assim, julgamos que Finley lança mão de uma analogia como estratégia de argumentação, estabelecendo uma inferência a partir de um contexto particular (o Sul dos Estados Unidos nas primeiras décadas dos Oitocentos). Do ponto de vista da lógica formal, Finley se pauta sobre o pressuposto de que uma circunstância particular causa um determinado tipo de consequência, de modo que causas semelhantes produziriam efeitos semelhantes. Logo, partindo de um caso específico, Finley parece se basear em uma premissa causal generalizante, qual seja, a noção de que a presença de uma dada circunstância se faz acompanhar, consequentemente, por um dado tipo de fenômeno (COPI 1978, p. 333).

Desta forma, a explanação elaborada por Finley adquire maior complexidade. No interior do conjunto $\beta$, a condição $<\mathrm{C} 1>$ não poderia ser encarada como o elemento necessário, posto que, se a condicionante $\langle\mathrm{F}\rangle$ tivesse sido colocada em prática, a condição $<\mathrm{C} 1>$ não teria se realizado ou, ao menos, teria sido deveras matizada. Quer dizer, se trata de uma forma de caracterizar a importância dos fatores causais recorrendo-se a um condicional contrafatual, isto é, mediante o recurso a uma situação que não ocorreu ou que, perante as evidências disponíveis, não pode ser atestada em larga escala. Como registra Nagel, embora a reflexão embasada em condicionais contrafatuais não deva ser encarada como especulação desprovida de fundamento, a mesma torna ainda mais aguda a natureza provável dos fatores causais em história, uma vez que "os juízos contrários ao fato" não comportam a possibilidade de averiguação em face das evidências disponíveis (NAGEL 1995a, p. 161-162). Posto assim, ao organizar sua argumentação a partir do implícito emprego de um elemento contrafatual, Finley desnuda uma perspectiva que concebe as relações de causalidade "em termos de mundos possíveis" (PESSOA JÚNIOR 2006, p. 39), no interior dos quais, acrescentemos, produzir-se-iam resultados diferentes. 
Diante disto, torna-se compreensível a ótica de que "a disponibilidade de uma oferta 'interna' de mão de obra tornava desnecessário que os possessores se esforçassem para recrutar trabalho escravo complementar" (FINLEY 1991, p. 155). Nestes termos, no interior do conjunto suficiente $\beta$ de causas assinaladas por Finley para a ocorrência do efeito $<\mathrm{E}>$, a condição $<\mathrm{C} 2>$ se situaria enquanto o elemento necessário.

E como poderíamos avaliar a explicação fornecida por Finley à luz do modelo de "frequência relativa" apresentado por Nagel? Relembremos, uma vez mais, que o referido esquema supõe que a presença simultânea de todos os condicionantes indicados não é necessária para a concretização de certo evento. Aqui, faz-se preciso reforçar que Finley defendesse, entre outras, a ideia de que a consolidação das fronteiras imperiais - a condição $\langle\mathrm{C} 1\rangle$ - teria se efetivado no alvorecer do século I d.C., ao passo que a baixa no número de escravos somente ganharia fôlego muitas décadas mais tarde, a partir do momento em que havia se cristalizado um efetivo nivelamento social e jurídico entre as camadas inferiores, livres e não livres, que viviam no interior do Império romano (FINLEY 1986, p. 119). Do que se pode concluir que Finley conferiu uma importância maior à condicionante $\langle\mathrm{C} 2>$ na medida em que a ocorrência de $\langle\mathrm{E}\rangle$, quando associada à $\langle\mathrm{C} 1\rangle$, teria sido relativamente menor se comparada com a presença de $<\mathrm{C} 2>$.

\section{Considerações finais}

Em resumo, a maior ou menor probabilidade que pode ser atribuída aos condicionantes causais, no que tange à escrita da história, se articula à organização e à hierarquização que os historiadores promovem ao empreenderem sua operação historiográfica. As divergências que por tantas vezes se verificam entre os ajuizamentos advogados pelos historiadores - como se observa no que respeita às explicações fornecidas por Anderson e Finley - ilustram justamente a perspectiva de que a avaliação da frequência relativa de ocorrência dos fenômenos não opera em conformidade com uma base quantitativa, tal como se denota no universo das ciências ditas naturais (NAGEL 1995b, p. 471).

Mais relevante ainda, o caráter qualitativo dos fatores causais, no que se refere aos estudos históricos, traz concretude e plausibilidade ao relato tecido pelos historiadores. Em simultâneo, isso contribui para definir o lugar que Anderson, Finley e tantos outros autores ocupam nos meandros do debate historiográfico. Neste sentido, o estabelecimento de explicações causais remete àquela "boa subjetividade" sobre a qual disserta Sabina Loriga, na medida em que os historiadores, empenhados em lançar luz aos significados obscuros do passado, devem igualmente aceitar um grau de controvérsia do qual não se pode furtar (LORIGA 2012, p. 256). Ora, se julgarmos que a controvérsia no reino dos historiadores passa pela elaboração de explicações que deem conta das possíveis causas dos acontecimentos, faz-se salutar que reflitamos sobre a maneira pela qual as relações de causalidade são estruturadas em meio às narrativas históricas. 


\section{Referências bibliográficas}

ANDERSON, P. Passagens da Antiguidade para o feudalismo. $2^{a}$ ed. São Paulo: Brasiliense, 1989.

ARRAIS, C. A. Filosofia analítica da história, o que é?. In: NICOLAZZI, F.; MOLLO, H.; ARAUJO, V. (orgs.). Caderno de resumos \& Anais do $4^{\circ}$. Seminário de História da Historiografia: tempo presente \& usos do passado. Ouro Preto: EdUFOP, 2010.

BERLIN, I. O conceito de história científica. In:

Estudos sobre a humanidade: uma antologia de ensaios. São Paulo: Cia. das Letras, 2002, p. 58-98.

$\mathrm{BLOCH}, \mathrm{M}$. Apologia da história ou o ofício do historiador. Rio de Janeiro: Jorge Zahar, 2001.

CARDOSO, C. F. S. Crítica de duas questões relativas ao anti-realismo epistemológico contemporâneo. Diálogos, Maringá, v. 2, p. 47-64, 1998.

CARR, E. H. A causa na história. In: Que é história? $3^{a}$ ed. Rio de Janeiro: Paz e Terra, 1982, p. 75-91.

CARVAlho, J. M. A guerra da Guerra. Folha de S. Paulo, São Paulo, 8 mar. 2003. Caderno Especial, Jornal de Resenhas, p. 5.

CHARTIER, R. A história ou a leitura do tempo. $2^{a}$ ed. Belo Horizonte: Autêntica, 2010.

COPI, I. M. Introdução à lógica. 2a ed. São Paulo: Mestre Jou, 1978.

DORATIOTO, F. Maldita guerra. São Paulo: Cia. das Letras, 2002.

DRAY, W. Explicando "O quê" em história. In: GARDINER, P. (org.). Teorias da história. $4^{a}$ ed. Lisboa: Fundação Calouste Gulbenkian, 1995, p. 494501.

FINLEY, M. I. A economia antiga. 2a ed. Porto: Afrontamento, 1986.

. Escravidão antiga e ideologia moderna. Rio de Janeiro: Graal, 1991.

GADDIS, J. L. The landscape of history: how historians map the past. Oxford: OUP, 2002.

GODFREY-SMITH, P. Explanation. In: Theory and reality: an introduction to the philosophy of science. Chicago; London: University of Chicago Press, 2003, p. 190-201.

HARPER, K. Introduction. Conquest and capital: the problem of slavery in Roman history. In: Slavery in the Late Roman world, AD 275-425. Cambridge: University Press, 2011, p. 3-32.

HEMPEL, C. G. A função das leis gerais em História. In: GARDINER, P. (org.). Teorias da história. $4^{a}$ ed. Lisboa: Fundação Calouste Gulbenkian, 1995, p. 421-435. 
JENKINS, K. A história repensada. 3a ed. São Paulo: Contexto, 2011.

LORIGA, S. O eu do historiador. História da historiografia, Ouro Preto, n. 10, p. 247-259, dez. 2012.

MUNSLOW, A. The Routledge companion to historical studies. $2^{\text {nd }}$ ed. London; New York: Routledge, 2006.

NAGEL, E. Problems in the logic of historical inquiry. In: The structure of science: problems in the logic of scientific explanation. $4^{\mathrm{a}}$ ed. London: Routledge; Kegan Paul, 1979, p. 547-605.

. Os condicionais contrafatuais. In: GARDINER, P. (org.). Teorias da história. 4a ed. Lisboa: Fundação Calouste Gulbenkian, 1995a, p. 158164.

Alguns problemas da lógica da análise histórica. In: GARDINER, P. (org.). Teorias da história. $4^{\mathrm{a}}$ ed. Lisboa: Fundação Calouste Gulbenkian, 1995b, p. 456-472.

PESSOA JÚNIOR, O. F. O que é uma causa? Cadernos de História da Ciência, São Paulo, v. 2, 2006, p. 29-45.

RINGER, F. Max Weber's methodology: the unification of the cultural and social sciences. Cambridge: Harvard University Press, 1997.

ROBERTS, C. The logic of historical explanation. University Park: Pennsylvania State University Press, 1996.

SCHAFF, A. A objetividade da verdade histórica. In: História e verdade. $6^{\mathrm{a}}$ ed. São Paulo: Martins Fontes, 1995, p. 279-310.

TUCKER, A. Historiographic explanation. In: Our knowledge of the past: a philosophy of historiography. Cambridge: Cambridge University Press, 2004, p. 185-207.

WEBER, M. A "objetividade" do conhecimento nas ciências sociais. Tradução de Gabriel Cohn. São Paulo: Ática, 2006. 